\title{
Design and Evaluation of Residential Building Alongwith Floating Column
}

\author{
Vivek Soni, M. P. Verma
}

\begin{abstract}
In the epoch of Construction multi-storied building with floating column plays a serious role in urban areas of India. These floating columns are mainly used for justifying the space availability within the construction and to urge good architectural view of the building. A residential high -rise building consisting of $G+7$ has been chosen for polishing off project work. The work was disbursed considering different cases of removal of columns in several positions and in various floors of the building. The building models are designed by using the software E-TABs 2018 and models of buildings are analyze and refined followed by IS 456-2000 guidelines.
\end{abstract}

Key Words: Floating columns, G+7, E-TABs, RCC frames, Building Evaluation, Building design, Shear force.

\section{INTRODUCTION}

Aforementioned, constructions of high - raise buildings in urban areas in India, the most problem arises within the arrangement of parking areas, and common lobbies etc. to beat this problem floating columns introduced into existence and now it's become an inescapable feature in most of the multi-storied buildings from the base level and distributed the load to the bottom. The phase floating column is additionally a perpendicular element which at its base level, reposes on a beam which may be a straight (vertical) member. The beams convey its load to the opposite column beneath. There are lots of projects in which floating columns are assumed, especially overhead the bottom floor, where transfer I-beam is engaged, so wide open space is on the market within the ground floor. These open spaces are also required for auditorium or purpose of parking. The transfer I-Beam must be developed and managed properly. The floating column worked as some extent load and this beams transfer the loads to the columns beneath it as deep as analyses is anxious, the column is commonly pretended pinned at the bottom and is therefore consider as a degree of load on the beam (transfer). The floating columns may be a vertical which reposes on a beam and does not have groundwork. But such column cannot be realize easy to practically compose, since truth column below the ending level are not constructed with care and hence finally cause to failure. Buildings with some of floating column that hangs up hat on beam at a transitional storey and don't go all the thanks to the foundation have discontinuities within the load sharing path. The floating columns are employed for the aim of architectonic view and site bearing. It may be analyzed by using E-TABs. The victuals of floating column are built as most of the buildings in all over the world are cover up the most possible area on a buildup area as per available by laws.

Revised Manuscript Received on October 10, 2020

Vivek Soni*, Department of Civil, Madhyanchal Professional, University, Bhopal, India.

M. P. Verma, Department of Civil, Madhyanchal Professional, University, Bhopal, India.

(C) The Authors. Published by Blue Eyes Intelligence Engineering and Sciences Publication (BEIESP). This is an open access article under the CC BY-NC-ND license (http://creativecommons.org/licenses/by-nc-nd/4.0/)

(C) Copyright: All rights reserved.
Published By:

Blue Eyes Intelligence Engineering and Sciences Publication

The floating column may be a upright (vertical) member which reposes on a beam but does not share the load on to the inspiration. The floating columns considered as point load on the beams and this beams transfer the load to the column beneath it. The columns may initiate on the primary or second or the other intermediate floor while resting on a beam. Usually columns rest on the muse to transfer loads from beams and slabs. However the floating column reposes on beam. The floating column in a very building as shown in Figure 1. At present the buildings are getting complex particularly the combination adopt one. There are lots of different usages of different floor so, hence to pursue it structural framework becomes burdensome as column on any stage (floor) would become a drawback. Even in residential building where there is a parking on lower base floor or huge piling are done to take advantage of ambiguities in local bylaws for gaining more free spaces, the lower floor needs no column spaces for straightforward movement of vehicles; while on upper floors which are more in number of the columns are designed supported room layout. They're also frequently used when there are shops on ground floor and residence on upper floors instead of finding an architectonic solving one comfortably take remedy to floating column and take away column on base stories, which may be a dangerous proposal.

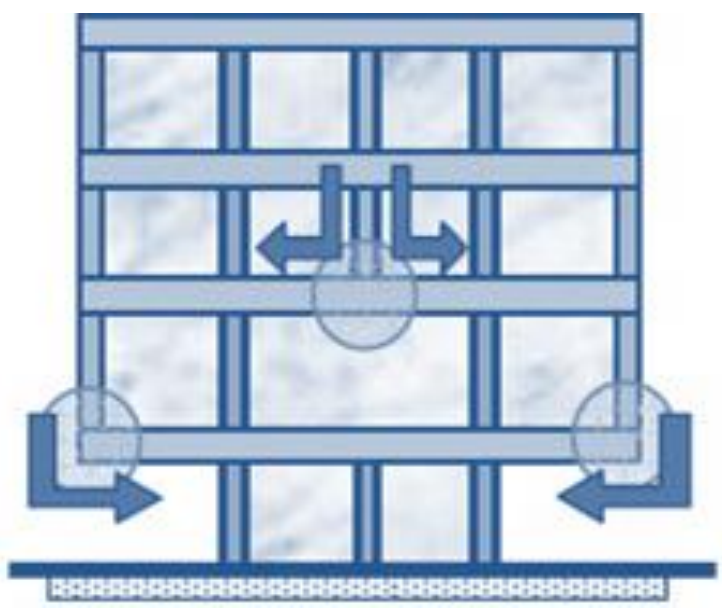

Fig.1. Floating column in Building

\subsection{TRANSFER BEAM}

Transfer beam are always need at places where columns location are uncertain, and also to transfers the force from columns upper to column beneath. To plan the transfers beam, considered the purpose load at the position where the column are ending. Thus time loads actually selected up to the degree of the column reflex.

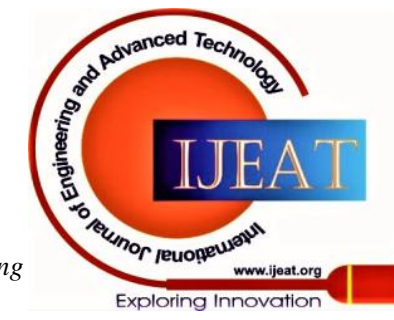




\section{Design and Evaluation of Residential Building Alongwith Floating Column}

Summate the opposite load which could work on the beams. Then check for shear and flexure, almost like a standard beam.

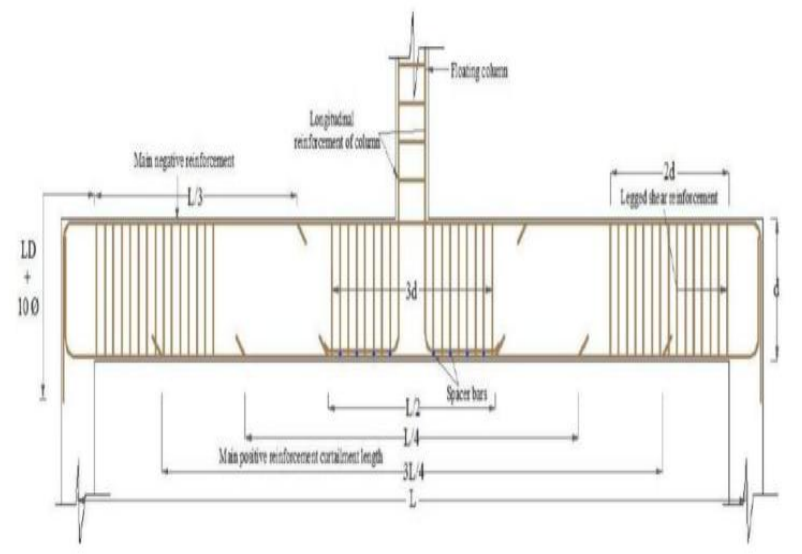

Fig.2. Transfer beam which support Floating Column

\section{OBJECTIVES AND SCOPE OF LABOR}

The objective of this work is to check the behavior of multistory buildings with floating columns. The bottom of the building frame is assumed to be fixed. Usually all multistoried buildings are of three types they're

- Load bearing construction

- Framed construction

- Composite construction

But among the above 3 types, within the present stage all the multistoried structure are framed construction which are durable. An engineering structure is an assembly of member of elements transferring the hundreds and providing a firm space to serve the specified foundation. The structural design may be a science and art of drafting, with recession and unique, a diuturnal structure like that which may safety and carry the force and may serve the required functions competently during its whole services. The complete methods of constructural devising and artistic talent required not only thought and visionary bright but also practical aspect, like suitable designs cipher and by requirement, protected by ample experience, institutions and judgment. The method of design commences with planning of a structure, primarily to fulfill the functional equipment of the user or client.The functional requirements and therefore the form of the artistic look in to ordinarily, while the durability, safety, goodwill and cost effective of the structures for its predetermined use all over the life.

\section{METHODOLOGY}

With relation to the national code, plan for the building is formed, and models are made. Analysis and style is finished by using architectural software like E-TABs 2018. The planning of reinforced cement concrete elements are distributed by as long as the minimum ambit of columns, beams and slabs. The scale of reinforced cement concrete elements are construct using MS office excel by considered the varied loads like burden, loading and curl load. The look is carry as per the rule i.e., IS 456-2000.

\subsection{MODEL FORMULATION}

The study is disbursed on a building with floating columns. The plan layout of the building is shown within the figure. The building is taken into account as residential building having $G+6$. Height of every storey is kept same as other prevalent data.

\subsection{REASERACH SIGNIFICANCE}

In urban areas, multi storey buildings are constructed by providing floating column for the varied purposes which are stated above. These floating column buildings aren't designated for earthquake loads. So these buildings don't seem to be designed for earthquake loads. So these buildings are unsafe in seismic prone areas. The project aims to make awareness about these issues in shock contrary structure of multi- storey buildings.

\subsection{LIMIT STATE METHOD}

In the limited state construction methods, non-deterministic parameters are determined supported observations confiscated a period of your time.

The target of design supported the limit state concept is to attain an appropriate probability that a structure won't become unserviceable in its life time for the utilization that it's intended, that is, it'll not reach a limit state. A structure with convenient and acceptable extend of trustworthiness, should be ready to withstand safely all loads that are susceptible to act on that throughout its life and it should also satisfy the serviceability requirements like limitations on deflection and cracking. It should even be ready to maintain the desired structural integrity during and after accidents like fires, explosions and native failure. Thanks to its realistic approach, limit state method is employed in design of structures. The foremost important limit states which must be examined in design are as follows:

\subsubsection{STATE OF COLLAPSE AND LIMITS}

State like this corresponds to the utmost load carry scope; infraction of destruction limit state entail failure within the feel that a apparently defined limit state of construction versatility has been better. But, it doesn't mean a whole crumple. Thus limit state may coincide to:

- Flexure

- Compression

- Shear

- Torsion

\subsubsection{LIMIT STATE OF SERVICEABILITY}

State of coincide to advancement of enormous formation and is employed for checking members within which degree of deformations may limits the utilization of the construction or its elements. This limit may coincide to:

- Deflection

- Cracking

- Vibration

\subsection{MODELING OF BUILDING}

Building for residential $(G+7)$ with floating column were selected for the research. The construction is taken into account to be positioned in Zone III as per IS 1893-2002. The building is designed using the structural software ETABs 2018. The diagnostic model of the construction includes all the elements that affect the volume (weight), durability, rigidity and sturdiness of construction. The construction structural consists of beams, columns, floating columns, slabs, grids slabs, shear wall and staircase.

Published By:

Blue Eyes Intelligence Engineering

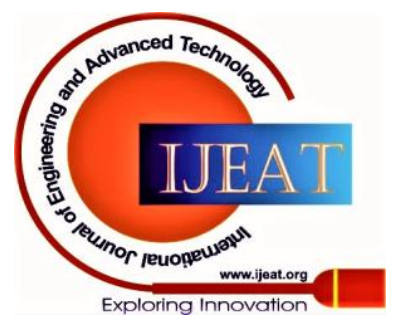




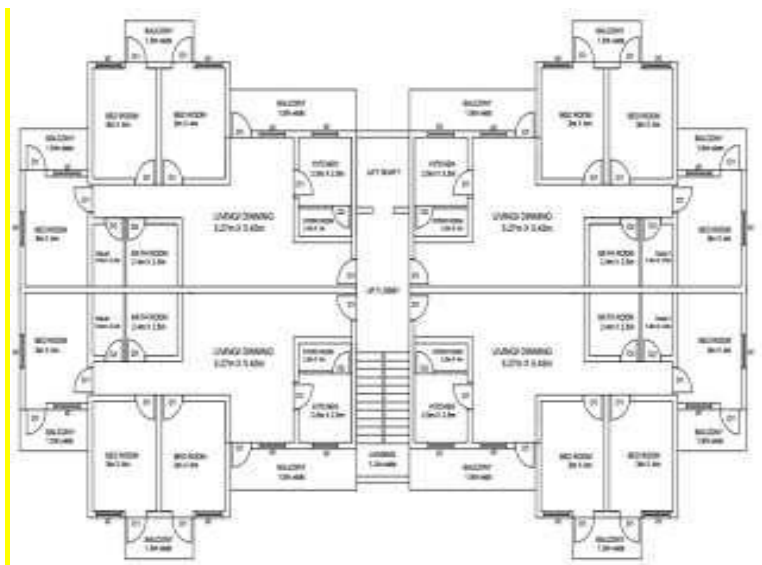

Fig.3. Typical architectural plan
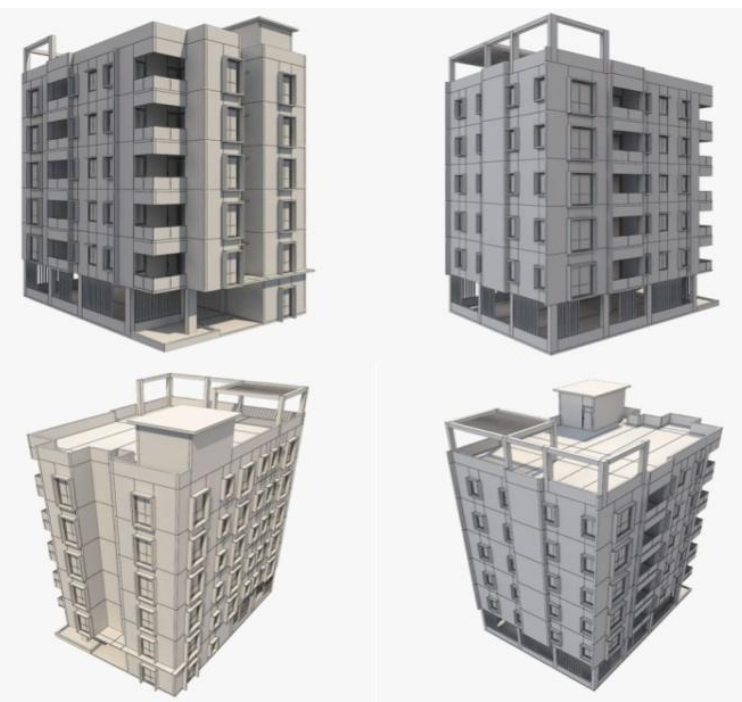

Fig.4. 3D Model of the Building

\subsubsection{DESCRIPTION OF THE BUILDING}

- Floor area $=521 \mathrm{~m} 2$

- Number of floor $=\mathrm{G}+6$

- Number of flat in each floor $=4$

- Number of rooms in each flat $=3$

- Floor to floor height $=3.6 \mathrm{~m}$

- Number of staircase $=1$

- Number of lifts $=1$

- Types of footing = Isolated footing

- Party hall \& Gym at top floor

Table - 1: Structural element with Properties

\begin{tabular}{lcc}
\hline \multirow{2}{*}{$\begin{array}{l}\text { RCC } \\
\text { Member }\end{array}$} & \multicolumn{2}{c}{ Properties } \\
\cline { 2 - 3 } Columns & $\begin{array}{c}\text { Grade of } \\
\text { Concrete }\end{array}$ & $\begin{array}{c}\text { Size in } \\
\text { mm }\end{array}$ \\
\hline \multirow{2}{*}{ Beams } & M30 & $230 \times 600$ \\
\cline { 3 - 3 } & \multirow{2}{*}{ M30 } & $230 \times 750$ \\
\cline { 3 - 3 } Slab & M30 & $230 \times 900$ \\
\hline
\end{tabular}

\subsection{TYPES OF LOADS}

Various forms of loads on a structures and requiring in designs are,

- Dead load

- Live load

- Wind load

\subsection{LIST OF IS CODE}

List of Code employed in analysis and style

- IS 456-2000 Plain and concrete

- IS-SP-16:1980 for R.C Column Design

- IS 875-1987 Part-I for load

- IS 875-1987 Part-II for loading

- IS 875-1987 Part-III for Wind Load

\subsection{LOAD COMBINATION}

A load consolidations result when quite load type action on the construction. Construction codes commonly determine a spread of load combinations along with weightings for every load type so as to confirm the security of the structure under different maximum expected loading scenarios..

Load combinations utilized in the look are,

-1.5(DL+LL)

-1.2(DL+LL+WL)

\section{ANALYSIS \& DESIGN}

The project requires the analysis of the building so as to seek out the magnitude of loads and their distribution. Hence, the software has been used for the analysis was ETABs 2018. The building was modeled with all the structural element and floating column. The varied loads that might be act on the structure were defined together with the properties of the structural elements. The analysis was dole out and also the loads and also the moments were determined. After which the structural elements are designed manually and are checked for safety.

\section{RESULTS \& DISCUSSION}

\subsection{BENDING MOMENT}

The BMD of beams for the $\mathrm{G}+7$ storied frame structure is as shown within the Figure 6. It's observed that the bending moment is bigger at mid span of every beam and reduces linearly because it proceeds towards the support of the beam span.

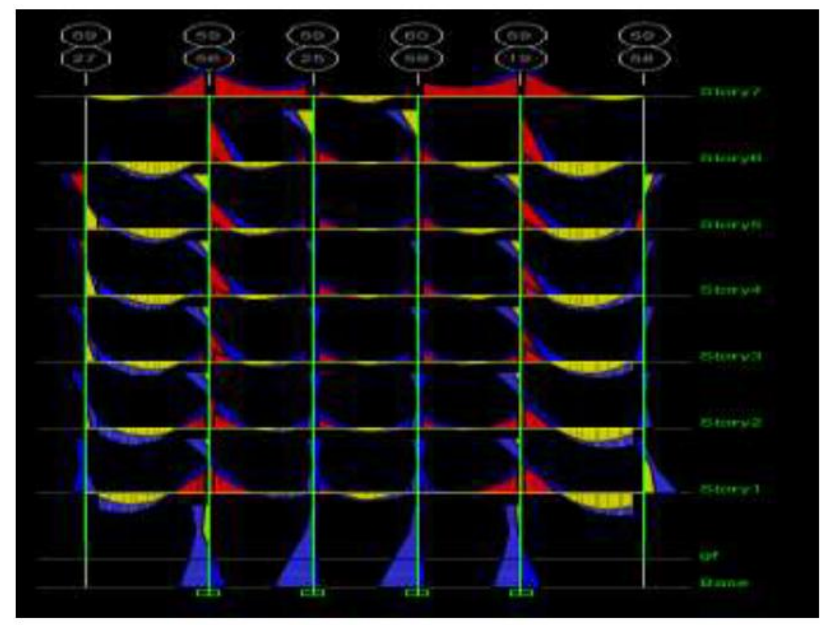

5.2 SHEAR FORCE

Fig.5. Bending Moment

The SFD for the required multi storied structure is as shown in Fig.6. it's observed that the shear force is larger towards the top portions of the beams that's towards the joint pertaining a beam and column. Shear force may additionally occur during a beam to beam junction.

Published By:

Blue Eyes Intelligence Engineering DOI:10.35940/ijeat.A1791.1010120

Journal Website: www.ijeat.org and Sciences Publication

(C) Copyright: All rights reserved.

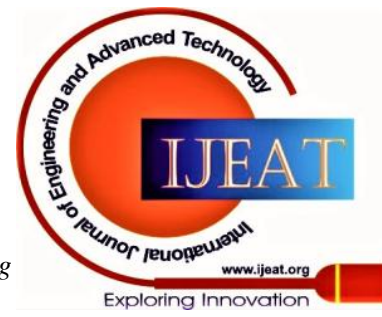




\section{Design and Evaluation of Residential Building Alongwith Floating Column}

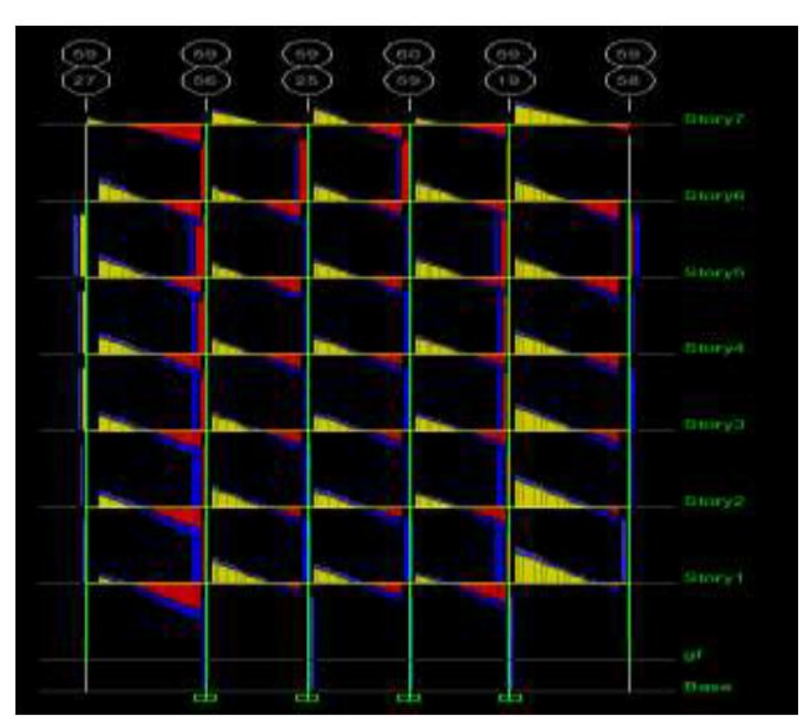

Figure 6. Shear Force

\subsection{FOOTING REACTIONS}

The below figure 7 shows the vertical load along the column of the structure to the bottom of the footing. These footing loads are accustomed determine the sort of footings similar to the soil condition and seismology. These column loads are grouped and wont to design a combined footing.

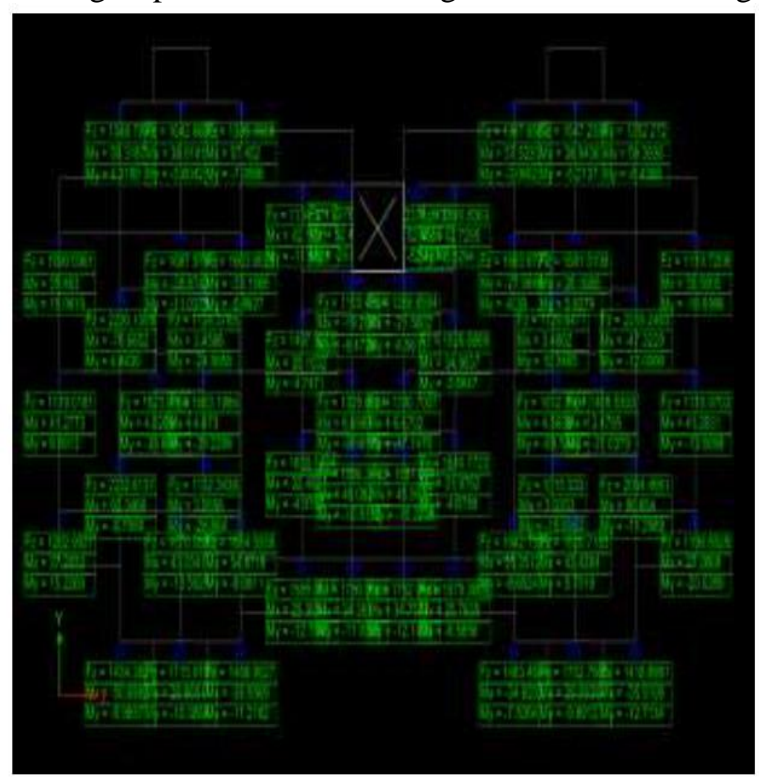

Fig.7. Reactions \& Moment for Footing

\subsection{ESTIMATION OF THE PROJECT}

Table - 2: Plinth Area Rate

\begin{tabular}{ccc}
\hline $\begin{array}{c}\text { Total cost of the } \\
\text { project(INR) }\end{array}$ & $\begin{array}{c}\text { Area of the } \\
\text { building } \\
\text { In Sq.ft. }\end{array}$ & $\begin{array}{c}\text { Plinth area } \\
\text { rate per Sq.ft }\end{array}$ \\
\hline $9,35,50,000$ & 7608 & $\mathbf{2 8 2 3}$ \\
\hline
\end{tabular}

\section{VI.}

\section{CONCLUSIONS}

Based on the test result, the subsequent conclusions were made:

- The use of floating columns in modern building are increasing vastly

- The optimum position to produce floating column is at 1st floor alternatively so moment, shear \& steel requirement of the full building is minimized.
- Hence provide the floating columns is advantageous in providing good floor space index but risky \& vulnerability of the building increases.

- Building supplied with the floating column shows more storey drift \& storey displacement as compare to putting together without floating column.

\section{REFERENCES}

1. Bureau of Indian Standards: IS-875, Part II (1987), Live Loads on Buildings and Structures, New Delhi, India.

2. Bureau of Indian Standards: IS-875, Part III (1987),

3. Wind Loads on Buildings and Structures, New Delhi, India.

4. IS 456-2000 Plain and Reinforced Concrete code.

5. BadgireUdhav S and Shaikh A.N, "Analysis ofMultistorey Building with Floating Column”, Volume no.4, Issue No. 9, 01 Sept. 2015, pp: 475-478.

6. Sasidhar T and P. Sai Avinash, "Analysis of MultistoriedBuilding with and without Floating Column Using ETABs",Volume 8, Issue 6, June 2017, pp:91-98.

Shivam Tyagi and B.S. Tyagi, "Seismic Analysis ofMultistorey Building with Floating Column", Volume 5, Issue No. 5, May 2018.

7. MD Najeeb Ur Rahman and B Rajkumar Singh, "Analysisof Multistorey Building with Floating Column”, Volume6, Issue No. 01, January-June 2018.

8. P. Pavan Kumar and D. Thrimurthi Naik, "Design andAnalysis of Residential Building with Floating ColumnsBy Considering Footing Design", Volume 2, Issue No. 6, June 2017.

9. Bureau of Indian Standards: IS-875, Part I (1987), DeadLoads on Buildings and Structures, New Delhi, India.

\section{AUTHOR PROFILE}

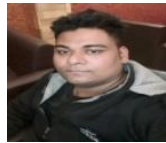

Vivek Soni, Professor, Department of Civil Engineering Madhyanchal Professional University, Bhopal

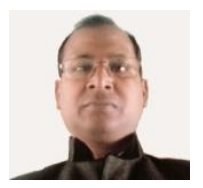

M. P. Verma, HOD, Department of Civil Engineering Madhyanchal Professional University, Bhopal

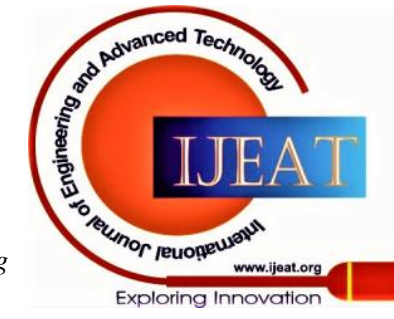

